\title{
Control of gene expression at the level of translation initiation
}

\author{
Randal J Kaufman
}

\author{
Howard Hughes Medical Institute, Ann Arbor, USA
}

\begin{abstract}
Protein synthesis is controlled at the level of translation initiation. Cells rapidly respond to environmental changes by disassembly of polysomes and recruitment of specific mRNAs from inactive ribonucleoprotein particles into polysomes active in translation. Recent insights have elucidated specific protein and RNA sequence interactions that are required to mobilize translation of selective mRNAs. The specificity of translational control provides a unique target to inhibit synthesis of specific polypeptides to control infectious disease as well as to control aberrant cell growth. In addition, greater understanding of the factors that limit protein synthesis is enabling the design of novel strategies to optimize protein expression and engineer host cells for enhanced growth and protein synthesis capacity.
\end{abstract}

Current Opinion in Biotechnology 1994, 5:550-557

\section{Introduction}

The rate of protein synthesis in eukaryotic cells is controlled by the amount and the translational efficiency of the mRNA and the activity of the translational machinery. The amount of mRNA is determined from gene transcription, mRNA processing, mRNA transport to the cytoplasm, and the half-life of the mRNA. The translational efficiency is determined by the mRNA primary and secondary structure. The activity of the translational machinery is determined by the availability of ribosomal subunits and of factors that influence initiation and elongation rates. Most translational control occurs at the level of initiation of protein synthesis. The rate of initiation is determined primarily by structure at the $5^{\prime}$ end of the mRNA and the activity of eukaryotic translation initiation factors (eIFs). Many eIFs that control translation initiation influence all cellular mRNAs; however, translation of many mRNAs is regulated through specific protein-mRNA interactions.

Our knowledge of the mechanism and regulation of protein synthesis in eukaryotic cells has emerged through the study of in vitro systems reconstituted with purified cellular components. Even so, our understanding of eukaryotic protein synthesis is poor compared with the process in prokaryotes, primarily as a result of a lack of genetic approaches in eukaryotes. One common approach to study translational control in intact eukaryotic cells is to perturb the cell and measure alterations in rates of either specific or of general protein synthesis. Different perturbations include stress such as heat shock, modulations of cell growth such as serum deprivation, and infection by different viruses. As viruses utilize the host cell machinery for viral mRNA and protein production as well as virion assembly, many viruses establish conditions within the host cell that allow them to dominate the cellular translational apparatus. An understanding of the mechanisms that viruses utilize to alter host translation has provided insights into cellular mechanisms that control translation initiation. In addition, the ability to increase or reduce the level of initiation factors through expression of wild-type, antisense, or mutant genes allows dissection of the mechanisms that regulate translation initiation in mammalian cells. The purpose of this review is to summarize very recent findings providing insight into the control of protein synthesis in mammalian cells that have potential impact on biotechnology.

\section{Translation initiation factors}

Translation is primarily regulated at the step of ribosome binding to mRNA. This process requires at least $10 \mathrm{dif}-$ ferent initiation factors that have been purified and characterized in vitro. Fig. 1 depicts the steps that occur to

\footnotetext{
Abbreviations

elF-eukaryotic initiation factor; elF-4E BP_elF-4E-binding protein; FGF_fibroblast growth factor; HIV_human immunodeficiency virus; HRI-hemin-regulated kinase from reticulocyte lysate; hsp-heat-shock protein; IRE-iron-responsive element; IRE-BP_-IRE-binding protein; IRES-internal ribosome entry site; ORF-open reading frame;

PABP—poly(A)-binding protein; PDGF—platelet-derived growth factor; PKR/DAI—RNA-dependent protein kinase; TAR-transcription activation region from HIV; TRBP-TAR-binding protein; UTR-untranslated region.
} 
initiate protein synthesis in mammalian cells. The two best studied reactions are the eIF2-promoted binding of Met-tRNA to $40 \mathrm{~S}$ ribosomal subunits and the recycling of eIF2, and binding of $\mathrm{mRNA}$ to ribosomes promoted by eIF4A, eIF4B, and eIF4F $[1,2]$. Translation is regulated in response to environmental stimuli by covalent modification, primarily phosphorylation, of components of the translational machinery $\left[3^{\bullet}\right]$.

\section{Ternary complex formation and elF-2 recycling}

Polypeptide chain synthesis initiates when a binary complex of eIF-2 and GTP forms and subsequently binds Met-tRNA. This ternary complex of eIF2, GTP, and initiator Met-tRNA binds the $40 \mathrm{~S}$ ribosomal subunit to generate a $43 \mathrm{~S}$ preinitiation complex. The $43 \mathrm{~S}$ preinitiation complex then binds the $5^{\prime}$ end of the mRNA and scans by migration in the $3^{\prime}$ direction until the first AUG codon in an appropriate context is reached. Next, the $60 \mathrm{~S}$ ribosomal subunit joins the complex in a step that requires hydrolysis of GTP bound to eIF-2. This initiation factor comprises three subunits $[\alpha(36 \mathrm{kDa}), \beta$ $(37 \mathrm{kDa})$, and $\gamma(52 \mathrm{kDa})]$ and is homologous to other trimeric GTP-binding proteins. GDP completely prevents eIF-2 from binding Met-tRNA. Thus, for eIF-2 to promote another round of initiation, GDP bound to eIF2 must be exchanged for GTP. This exchange reaction requires catalysis by the guanine nucleotide exchange factor or eIF-2B, which is a protein complex composed of five subunits $(85 \mathrm{kDa}, 67 \mathrm{kDa}, 52 \mathrm{kDa}$, $37 \mathrm{kDa}$, and $27 \mathrm{kDa}$ ). The control of the eIF-2 recycling activity is a primary regulatory step in protein synthesis and is controlled at one level by the phosphorylation state of the alpha subunit of eIF-2 (eIF-2 $\alpha)\left[3^{\bullet}\right]$.

\section{Kinases that phosphorylate elF-2}

Three protein kinases, which are well characterized, phosphorylate a single residue $(\operatorname{Ser} 51)$ in eIF-2 $\alpha$ [4॰]. These are the general control of amino acid utilization kinase from Saccharomyces cerevisiae (GCN2), the hemin-regulated kinase from reticulocyte lysate (HRI), and the double-stranded RNA-activated protein kinase (PKR or DAI). Phosphorylation of eIF- $2 \alpha$ stabilizes the eIF2-GDP-eIF2B complex and consequently prevents GTP exchange, eIF2 recycling, and further initiation events. It is proposed that translation arrest results from sequestration of eIF-2B by phosphorylated eIF-2. Small changes in the phosphorylation status of eIF-2 can dramatically effect protein synthesis because the concentration of eIF-2B in the cell is approximately an order of magnitude less than that of eIF-2.

The eIF-2 $\alpha$ kinases can regulate both global as well as specific mRNA translation. The best studied example of control of specific mRNA translation occurs in $S$. cerevisaie, where amino acid starvation activates GCN2 kinase to phosphorylate eIF-2 $\alpha\left[5^{\bullet \bullet}\right]$. This specifically stimulates GCN4 mRNA translation through the ability

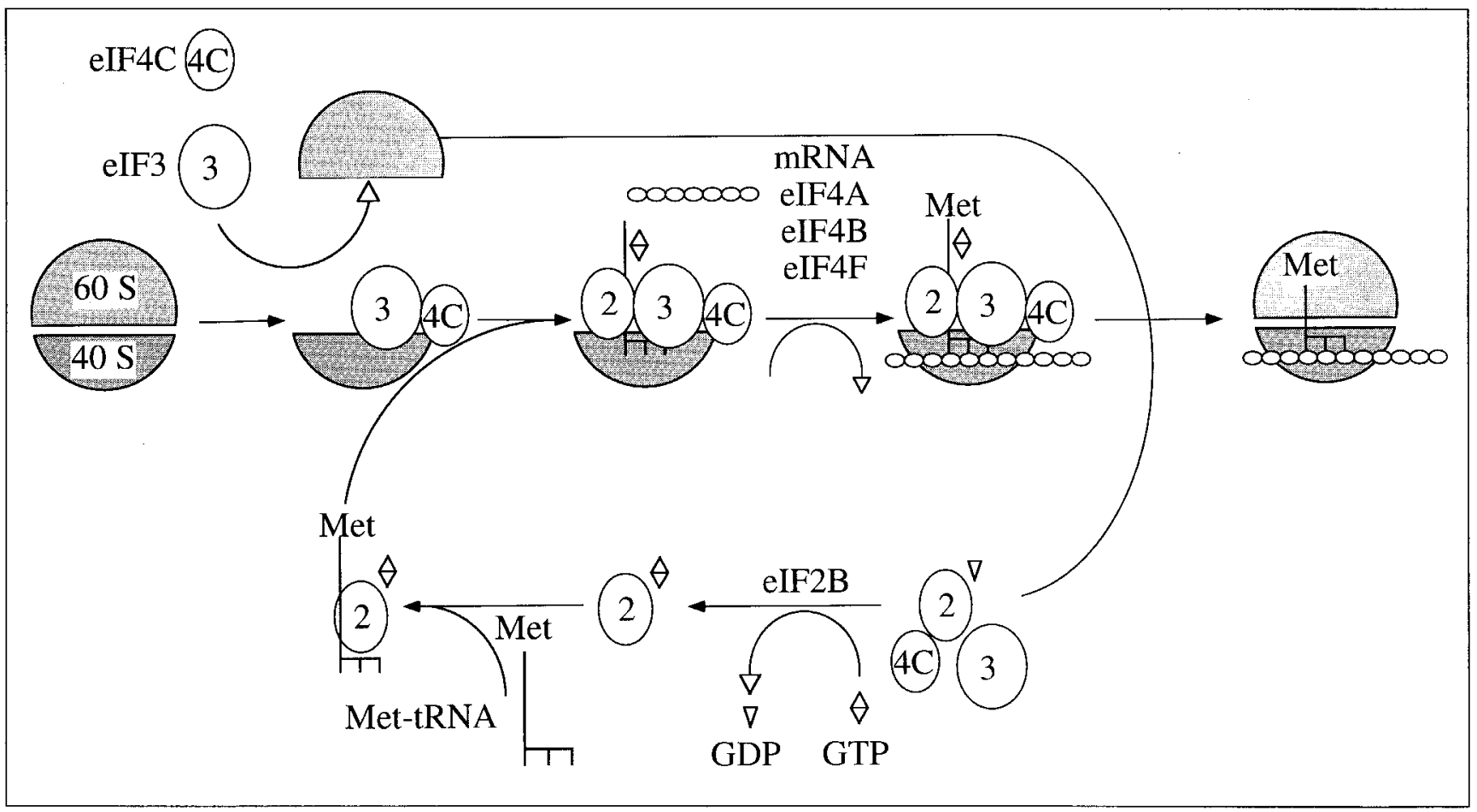

Fig. 1. Initiation of protein synthesis. The two major control steps in translation initiation are depicted. In the first step, the ternary complex (elF-2-GTP-Met-tRNA) promotes binding of the $40 \mathrm{~S}$ ribosomal subunit to the mRNA. In the second step, elF-4A, elF-4B, and elF-4F promote unwinding of secondary structure at the $5^{\prime}$ end of the mRNA. The elf-2 cycle is depicted, showing the exchange of GTP (diamond) with GDP (inverted triangle) that is required to continue initiation events. The points where initiation factors elF-2 (2), elF-3 (3), and elF-5A (4C) act are also shown. 
to scan through open reading frames (ORFs) upstream of GCN4 and allows initiation at the GCN4 AUG initiation codon. The presence of the upstream ORFs is required to mediate GCN2 translational control of GCN4. Analogous examples of this type of mRNAspecific control mediated by eIF- $2 \alpha$ phosphorylation are likely to occur in higher eukaryotic cells. Two examples have been described where mRNAs both contain cis-acting elements that mediate PKR activation in a localized manner and inhibit translation where general mRNA translation is not affected. The S1 gene from reovirus is not translated in the absence of the sigma 3 gene product, whereas other mRNAs are efficiently translated [6*0]. In addition, plasmid-derived mRNAs are inefficiently translated in DNA transfection experiments [ $7^{\bullet \bullet}$ ]. It is proposed that this selective translational repression is mediated through PKR activation and phosphorylation of eIF-2 in the vicinity of the mRNA [7*•].

Expression of non-functional PKR mutants perturbs cell growth and transforms NIH 3T3 cells [8,9]. This observation has generated interest in the role of PKR activation in translational control and in other cellular processes that may control cell growth. A minimum of $50 \mathrm{bp}$ duplex of double-stranded RNA can activate PKR, in addition to a variety of more complex RNA structures $[10,11]$. Double-stranded RNA interacts with two conserved double-stranded RNA-binding domains in the amino terminus and probably promotes dimerization of the kinase to elicit autophosphorylation [12]. The phosphorylated kinase is constitutively active, no longer requires double-stranded RNA for activity, and can utilize eIF- $2 \alpha$ as a substrate. In mammalian cells, transcription of PKR is induced as part of the cellular antiviral response to interferon. Interferonresistant viruses have evolved specific gene products that inhibit activation of PKR. These include the RNA polymerase III transcripts VA RNA and EBER RNA from adenovirus and Epstein-Barr virus, respectively [13], the E3L and K3L gene products from vaccinia virus [14], and the sigma 3 gene product from reovirus [15]. These gene products either directly bind PKR and inhibit its activity (e.g. the RNA polymerase III gene products and $\mathrm{K} 3 \mathrm{~L}$ ) or compete with PKR to bind double-stranded RNA, thus preventing activation (e.g. E3L and the sigma 3 gene products). Recently, two cellular gene products, the human immunodeficiency virus (HIV) RNA target sequence (TAR)-binding protein (TRBP) [7••] and a protein activated upon influenza virus infection (p58)[16], have been shown to inhibit the activity of PKR. Overexpression of p58 transforms NIH3T3 cells, implicating its importance in growth control [17-0]. As it is unlikely that these cellular gene products are solely responsible for down-regulation of PKR upon viral infection, future studies are required to elucidate how these cellular gene products regulate PKR activity, which in turn, regulates cellular mRNA translation.

The observed tumor-suppressing activity of PKR may explain the anti-proliferative effects of interferon. At present, it is not known if the observed tumor-suppressing activity of PKR is mediated by eIF- $2 \alpha$ phosphorylation to inhibit translation or whether PKR phosphorylates another substrate involved in growth control. Recent experiments indicate that PKR can activate the transcription factor NF- $\kappa B$, possibly through phosphorylation of its inhibitor, I $K B\left[18,19^{\bullet \bullet}\right]$. In addition, double-stranded RNA can activate NF- $\kappa$ B responsive genes (i.e. those encoding intercellular adhesion molecule 1, vascular cell adhesion molecule 1 , and E-selectin) in endothelial cells, through a mechanism that likely requires PKR activation [20]. It is interesting that PKR is also activated upon calcium mobilization induced by ionophore treatment (SR Srivastava, RJ Kaufman, unpublished data), suggesting that PKR may participate in a more general growth factor signal transduction pathway, as previously suggested $[21,22]$.

\section{Control of elf- $2 \alpha$ phosphorylation by stress conditions}

Inhibition of protein synthesis correlates with eIF-2 $\alpha$ phosphorylation in response to a wide variety of different stimuli, including heat shock, serum deprivation, glucose starvation, amino acid starvation, exposure to heavy metal ions, and other inducers of the stress response, and upon viral infection and plasmid DNA transfection [3*]. The importance of this modification in translational control was demonstrated by expression of a Ser51 $\rightarrow$ Ala mutant of eIF- $2 \alpha$ that cannot be phosphorylated. In cells that express this mutant, protein synthesis is not inhibited upon activation of PKR following viral infection or DNA transfection [7*0]. In addition, expression of this mutant protects cells from both inhibition of protein synthesis and reduction in eIF-2B activity upon heat-shock treatment $\left[23,24^{\bullet}\right]$ This is the strongest evidence that eIF- $2 \alpha$ phosphorylation reduces functional eIF-2B activity in vivo. Regulation of eIF- $2 \alpha$ activity may also occur through regulation of dephosphorylation, but the phosphoprotein phosphatase(s) involved have not yet been characterized in detail. An eIF-2associated protein of $67 \mathrm{kDa}$ that can protect eIF- $2 \alpha$ from HRI-mediated phosphorylation has been isolated from reticulocyte lysate and the gene recently cloned [25]. This unusual protein contains multiple O-linked $\mathrm{N}$-acetylglucosamine residues that are required to protect eIF-2 $\alpha$ from phosphorylation. An understanding of the mechanisms that regulate phosphorylation and dephosphorylation of eIF- $2 \alpha$ will help elucidate how phosphorylation of eIF- $2 \alpha$ mediates control of translation.

Upon heme deprivation in reticulocyte lysates, HRI is activated from a latent to an active form by autophosphorylation. Hemin promotes intersubunit disulfide bond formation in both latent and activated phosphorylated HRI. Recent studies have shown that HRI is in a complex with the cellular heat-shock proteins of $70 \mathrm{kDa}(\mathrm{hsp} 70)$ and $90 \mathrm{kDa}$ (hsp90) in an inactive form in hemin-supplemented lysates, and dissociates from hsp 70 
upon activation [26*]. Pretreatment of cells with heat induces hsp70 and hsp90 expression and abrogates the inhibitory effect of subsequent heat shock on protein synthesis, suggesting that heat-shock proteins may also play a role in the activation of the eIF- $2 \alpha$ kinase that occurs in response to heat shock. Although the eIF$2 \alpha$ kinase that is activated upon heat shock has not yet been identified, results suggest that denatured proteins bind and sequester heat-shock proteins, such as hsp70, and lead to activation of an HRI-like kinase in response to heat shock.

\section{Factors that promote mRNA unwinding and ribosome binding to $\mathrm{mRNA}$}

In contrast to initiation in prokaryotes, ATP is required for translation initiation in eukaryotes. The best understood function for the $5^{\prime} \mathrm{m}^{7} \mathrm{G}$ cap structure is its ability to promote $40 \mathrm{~S}$ ribosomal subunit binding to mRNA in an ATP-dependent manner. A cap-binding protein complex, eIF-4F, which comprises three subunits (eIF $4 \alpha$, eIF- $4 \beta$, and eIF- $4 \gamma$ ), functions to 'melt' RNA secondary structure within the $5^{\prime}$ end of the mRNA in an ATP-dependent manner. The integrity of this complex is required to promote cap-dependent translation initiation, and recent studies suggest this complex may also promote cap-independent translation initiation [27]. Intriguingly, recent observations suggest this complex is also involved in coupling translation initiation at the $5^{\prime}$ end of the mRNA with polyadenylation at the $3^{\prime}$ end of the mRNA.

\section{The small cap-binding protein, elF-4E}

Eukaryotic initiation factor $4 \mathrm{E}$ is a monomeric cellular protein that also exists as the eIF- $4 \alpha$ subunit of eIF$4 \mathrm{~F}$. It is a $24 \mathrm{kDa}$ protein that binds directly to the $5^{\prime} \mathrm{m}^{7} \mathrm{G}$ cap structure in an ATP-independent manner, and evidence has accumulated that the activity of this factor plays a crucial role in cell growth and differentiation. It is thought that eIF-4E is probably the first factor to interact with an mRNA to initiate translation. Over-expression of eIF-4E transformed NIH 3 T3 cells, deregulated growth in HeLa cells, and cooperated with nuclear oncoproteins, such as v-myc, to transform rat primary embryo fibroblasts [28]. Over-expression of eIF-4E activated ras and over-expression of GAP, the negative effector of ras, caused reversion of the eIF-4E-mediated transformed phenotype [29]. Reduction of eIF-4E levels caused a reversal of ras-mediated transformation and a general inhibition of protein synthesis with an increase in translation of mRNAs encoding heat-shock proteins [30,31]. Finally, over-expression of eIF-4E induced mesoderm formation in Xenopus laevis embryos [32*0]. These observations suggest that
eIF-4E is an early downstream target of growth stimulatory molecules [e.g. platelet-derived growth factor (PDGF), epidermal growth factor, tumor necrosis factor, insulin, etc].

The activity of eIF-4E is increased by phosphorylation that occurs upon increased protein synthesis in response to growth factor stimulation [3*]. Dephosphorylation of eIF-4E correlates with inhibition of cellular protein synthesis in response to heat shock and viral infection. Although initial studies suggested Ser 53 as a phosphorylation site, this residue has not been confirmed as the primary site in subsequent studies ([33]; RE Rhoads, personal communication). Recently, two eIF-4E binding proteins (eIF-4E BPs) have been cloned and shown to negatively regulate eIF-4E activity and inhibit translation of cap-dependent mRNAs, but not translation from internal ribosome entry site (IRES) (see below) sequences (G Belsham, N Sonenberg, personal communication). Insulin-mediated stimulation of protein synthesis was associated with phosphorylation of the eIF-4E BP and dissociation of eIF-4E BP from eIF-4E. Future studies should elucidate how the activity of eIF-4E is regulated in vivo.

\section{The large cap-binding protein complex, elF-4F}

Eukaryotic initiation factor $4 \mathrm{~F}$ is a heterotrimer of eIF$4 \alpha$, eIF-4 $\beta$ (eIF-4A), a protein that has ATPase and RNA helicase activity, and eIF- $4 \gamma$ (p220). The primary role identified for eIF-4F appears to be its ability to 'melt' secondary structure of mRNA in an ATPdependent manner. The cloning and mutational analysis of eIF-4A demonstrated that this factor is a member of a gene family that exhibits ATP-dependent helicase activities, which are critical for cap-dependent and capindepenent translation [34]. This family of related ATPases contains the consensus sequence motif DEAD box that is present in a special version of the $B$ motif of ATP-binding proteins [35]. The helicase activity of eIF-4A is more effective as part of eIF-4F and is stimulated by the presence of eIF-4B, an RNA-binding protein. Eukaryotic initiation factor $4 B$ exhibits a highly variable degree of serine phosphorylation that correlates with initiation activity. It is dephosphorylated in response to heat shock and becomes phosphorylated after addition of serum $\left[1,3^{\bullet}\right]$.

Although the role of eIF- $4 \gamma(\mathrm{p} 220)$ in translation initiation is unknown, its importance is suggested from picornaviral infection where proteases induce p220 cleavage and inactivation that roughly coincides with inhibition of host protein synthesis [36]. Even so, recent results suggest that cleavage of $\mathrm{p} 220$ is not directly responsible for the shutoff in host mRNA translation $[36,37]$. Recently, the cDNA clone encoding eIF- $4 \gamma$ has been isolated, and viral-induced cleavage sites were identified that should provide the basis for experiments to directly test the role of p220 cleavage in protein synthesis [38]. 


\section{mRNA}

\section{structural requirements}

Although the precise mechanism by which eukaryotic ribosomes initiate at appropriate AUG codons within mRNA involves numerous components and is regulated by many steps, a substantial amount of evidence supports a scanning model for translation initiation $[39,40]$. This model proposes that a $40 \mathrm{~S}$ ribosomal subunit binds to the $5^{\prime}$ end of the mRNA and migrates in the $3^{\prime}$ direction until it encounters the first AUG triplet which, if present in an appropriate context, can efficiently serve as the initiator codon. Comparison of the sequence context of the initiation codon within eukaryotic mRNAs has demonstrated that the most favored initiation site has the following consensus sequence: $5^{\prime}$-CCA/GCCAUGG-3' (where the initiation codon is italicized) [39].

Of paramount importance is the purine in the -3 position and secondarily, the guanine in the +4 position. Even so, it is now appreciated that many viral and cellular mRNAs have specific sequence and secondary structural elements promoting internal ribosome binding that is independent of the $5^{\prime}$ cap structure.

\section{The $5^{\prime}$ untranslated region and cap structure}

The primary determinants for the efficiency by which ribosomes bind mRNA and initiate polypeptide chain synthesis are the structural features within the $5^{\prime}$ noncoding region of the mRNA. In addition to the $5^{\prime}$ cap structure, eukaryotic mRNAs possess a $5^{\prime}$ non-coding region of variable length preceding the initiator methionine codon. The primary sequence and secondary structure within this region can greatly influence translational efficiency. Most long $5^{\prime}$ untranslated regions contain one or more AUG codons followed shortly by in-frame termination codons. Although little evidence suggests that these small ORFs have general biological significance, examples have been found where the small polypeptides are translated from several viral $m R N A s$ and where mutations within these ORFs can alter initiation at the primary downstream AUG within that mRNA (see [41] and references therein). Experimental evidence has accumulated that increased secondary structure within the 5 ' untranslated region of the mRNA results in reduced translational efficiency [39]. Increased suppressive effects on translation occur when the structure is positioned close to the $5^{\prime}$ cap, and more stable hairpin structures are required to inhibit downstream translation when their distance from the $5^{\prime}$ cap is increased. A $-60 \mathrm{kCal}$ structure can cause a $40 \mathrm{~S}$ ribosome to pause immediately upstream of the structure, providing strong supporting evidence for the scanning model of translation initiation. Cellular mRNAs that have long $5^{\prime}$ untranslated regions with potential to form secondary structures and dramatically influence translation include collagen, $c-A b l, c-J u n$ , c-Myc, and PDGF A chain. The transforming activity of eIF-4E may result from increased translation initiation of this class of mRNAs.

\section{Specific structures within mRNA that mediate selective translational control}

The best studied example of a $5^{\prime}$ untranslated region that regulates translation initiation in higher cells is that of ferritin biosynthesis controlled by iron (see recent review [42*0]). Two proteins responsible for the uptake and detoxification of iron in higher eukaryotic cells are the transferrin receptor and ferritin, respectively. The expression of both these proteins is regulated by iron. Whereas ferritin synthesis is inhibited in response to iron deprivation, the synthesis of the transferrin receptor increases. The reduction in ferritin synthesis is mediated at the level of translation initiation, whereas the increase in transferrin receptor is mediated through increased mRNA stability. A 30 bp RNA sequence element is necessary and sufficient for the ferritin mRNA to be translationally controlled by iron. This ironresponsive element (IRE) located in the $5^{\prime}$ end of the ferritin mRNA forms a stable stem-loop structure that is required for iron-mediated translational regulation. A $90 \mathrm{kDa}$ IRE-binding protein (IRE-BP) both specifically binds the IRE in the $5^{\prime}$ end of the ferritin mRNA and acts as a translational repressor. IRE-BP exists in two conformations, depending on the oxidation-reduction potential. In the absence of iron, two sulfhydryls within the protein are free, and this conformation exposes a high-affinity IRE-binding site $\left(\mathrm{K}_{\mathrm{d}}=20 \mathrm{pM}\right)$. When iron is abundant, these sulfhydryls form a disulfide bond that reduces the IRE-binding site affinity to $3 \mathrm{nM}$ and permits translation of the ferritin mRNA. This 'sulfhydrylswitch' may constitute a general mechanim by which protein-nucleic acid interactions are regulated. The ironinduced translational stimulation was used in combination with a metallothionein-inducible promoter to engineer cells for a 500-fold induction of gene products derived from specifically desired mRNAs [43].

Another example of selective mRNA translational control mediated by specific mRNA sequences is that of the ribosomal proteins and elongation factors, such as eukaryotic elongation factor $1 \alpha$. This family of transcripts contains $m R N A$ s with a polypyrimidine tract immediately after their $5^{\prime}$ cap structure. These mRNAs are selectively translated upon phosphorylation of the 40 S ribosomal protein S6. S6 is phosphorylated upon activation of $\mathrm{p} 70^{\mathrm{s}} 6 \mathrm{k} / \mathrm{p} 85^{\mathrm{s}} 6 \mathrm{k}$. The immunosuppressant rapamycin blocks activation of $\mathrm{p} 70^{\mathrm{s}} 6 \mathrm{k} / \mathrm{p} 85^{\mathrm{s}} 6 \mathrm{k}$, reduces phosphorylation of $\mathrm{S} 6$, and selectively blocks translation of the polypyrimidine tract containing mRNAs [44**]. These findings provide a plausible mechanism for rapamycin inhibition of mitogen induction of $T$ cells entering $S$ phase. It will be interesting to find out whether similar immunosuppressant effects may be obtained through the use of anti-sense oligonucletides di- 
rected toward the polypyrimidine tract on these selective mRNAs.

\section{The internal ribosome entry site}

Many reports describing mRNAs that can be translated in a cap-independent manner in mammalian cells have now appeared $[37,45]$. The best studied examples are picornavirus $m R N A s$ that have an extremely long $5^{\prime}$ untranslated region (650-1300 bases) containing multiple upstream AUG codons. The mechanism for capindependent translation of picornaviral mRNA (e.g. poliovirus and encephalomyelocarditis virus) occurs by internal binding of ribosomes within the $5^{\prime}$ untranslated region of the mRNA without scanning from the $5^{\prime}$ end. Although specific proteins that bind these IRES sequences have been identified (e.g. eIF-2, the polypyrimidine tract binding protein $\mathrm{p} 57$ [46], or the La autoantigen p52 [47]), their significance in internal initiation is presently unknown. The IRES provides efficient translation of an adjacent downstream coding region, regardless of its position within the mRNA. Technological advances in expression technology derived from use of the IRES to express dicistronic mRNAs [48]. The IRES upstream from a selectable marker coding region was also used to select for homologous recombination in mammalian cells [49].

A number of cellular mRNAs that utilize internal ribosome binding include the immunoglobulin-binding protein BiP [50], Antennapedia [51], and fibroblast growth factor (FGF)-2 [52॰]. FGF-2 (basic FGF) is particularly interesting because three CUG initiation codons occur upstream of the classical AUG initiation codon. Initiation from one of these CUG codons results in a nuclearlocalized form of FGF that immortalizes cells, whereas initiation at the classical AUG codon results in a cytoplasmic form of FGF-2 that transforms cells $\left[53^{\bullet}, 54\right]$. A $100 \mathrm{kDa}$ protein that binds the $5^{\prime}$ untranscribed region (UTR) was identified and its presence in different cell types coincides with utilization of the CUG codon and the transformed phenotype [52॰].

\section{The role of the $3^{\prime}$ poly $(\mathrm{A})$ tail in translation initiation}

Most eukaryotic mRNAs have a polyadenylic acid [poly(A)] tract at their $3^{\prime}$ termini. These poly(A) tails are added post-transcriptionally in the nucleus with an initial length of 200-250 adenylate residues. Following transport to the cytoplasm, the poly(A) tail is shortened to a steady-state length of 50-70 adenylate residues. The poly(A)-binding protein (PABP) is required for poly $(\mathrm{A})$ shortening and for joining of the $60 \mathrm{~S}$ ribosomal subunit. Increasing evidence suggests that the poly $(A)$ tail plays a key role in translation initiation at the $5^{\prime}$ end of the mRNA $[55,56]$. In the absence of poly(A), mRNAs are recruited into the $80 S$ initiation complex at a reduced efficiency. Translation of mRNA is inhibited upon addition of excess poly(A) to in vitro translation reactions and may may result from competition for a limiting factor that binds both the $5^{\prime}$ cap structure and the poly(A) tail, possibly eIF-4F and eIF-4B [57०]. Poly(A) may bind and induce a conformational change in a factor required for translation. Cloning of the poly(A)-binding protein (PABP) and genetic disruption in S. cerevisiae demonstrated that PABP facilitates $80 \mathrm{~S}$ initiation complex formation and is required for poly(A) tail shortening. Upon selection for reversion, independent extragenic suppressor mutants were identified that allow translation initiation without significantly affecting the poly(A) tail shortening defect. These suppressor mutations result in an increase in the amount of the $60 \mathrm{~S}$ ribosomal subunit.

\section{Conclusions}

As the mechanisms that control mRNA recruitment onto polysomes become clear, it will be possible to engineer cells to produce high levels of specific polypeptides at desired times. The ability to control the utilization of any particular mRNA in a host cell that is producing a particular protein product should allow optimization of the expression level and growth properties of the cell to maximize product yield. Understanding how specific mRNAs are chosen for translation initiation will provide avenues to intervene in very selective ways to prohibit synthesis of specific polypeptides, such as oncogenes or viral polypeptides, and to eventually design specific agents to prevent infectious disease and cancer.

\section{References and recommended reading}

Papers of particular interest, published within the annual period of review, have been highlighted as:

- of special interest

- of outstanding interest

1. Hershey JWB: Translational Control in Mammalian Cells. Annu Rev Biochem 1991, 60:717-754.

2. Merrick WC: Mechanism and Regulation of Eukaryotic Protein Synthesis. Microbiol Rev 1992, 56:291-315.

3. Rhoads RE: Regulation of Eukaryotic Protein Synthesis by IniSee $\left[4^{\bullet}\right]$

4. Samuel CE: The elF-2 $\alpha$ Protein Kinases, Regulators of Transla- tion in Eukaryotes from Yeasts to Humans. / Biol Chem 1993, 268:7603-7606.

This article and $\left[1,2,3^{\bullet}\right]$ are very thorough recent reviews that provide a good overview on the regulation of eukaryotic protein synthesis.

5. Vazquez de Aldana CR, Hinnebusch AG: Mutations in the - GCD7 Subunit of Yeast Guanine Nucleotide Exchange Factor elf-2B Overcome the Inhibitory Effects of Phosphorylated elf2 on Translation Initiation. Mol Cell Biol 1994, 14:3208-3222. In this paper, the authors describe the power of genetic selection for the identification of interacting proteins in the control of GCN4 translation. They demonstrate that mutations in GCD7, a subunit of elF-2B, can complement the effect of phosphorylated elF- $2 \alpha$. 
6. Henry GL, MCCormack SJ, Thomis DC, Samuel CE: Mechanism -. of Interferon Action Iranslational Control and the RNA-Dependent Protein Kinase (PKR): Antagonists of PKR Enhance the Translational Activity of mRNAs that Include a 161 Nucleotide Region from Reovirus S1 mRNA. / Biol Regulat Homeostat Agents 1994, 8:in press.

This paper describes the idenfication of an RNA element in the reovirus S1 mRNA that activates PKR to selectively inhibit translation of S1 mRNA.

7. Park H, Davies MV, Langland JO, Chang HW, Nam YS, - Tartaglia 1, Paoletti E, lacobs BL, Kaufman RI, Venkatesan S: TAR RNA-Binding Protein is an Inhibitor of the InterferonInduced Protein Kinase PKR. Proc Natl Acad Sci USA 1994, 91:4713-4717.

Shows that the HIV TAR RNA-binding protein can potentiate translation of selective mRNAs that are not translated as a result of localized activation of PKR. A model is presented for how PKR activation may preferentially affect translation of specific mRNAs.

8. Koromilas AE, Roy S, Barber GN, Katze MG, Sonenberg $\mathrm{N}$ : Malignant Transformation by a Mutant of the IFNInducible dsRNA-Dependent Protein Kinase. Science 1992, 257:1685-1689.

9. Meurs EF, Galabru J, Barber GN, Katze MG, Hovanessian AG: Tumor Suppressor Function of the Interferon-Induced DoubleStranded RNA-Activated Protein Kinase. Proc Natl Acad Sci USA 1993, 90:232-236.

10. Manche L, Green SR, Schmedt C, Mathews MB: Interactions between Double-Stranded RNA Regulators and the Protein Kinase DAl. Mol Cell Biol 1992, 12:5238-5248.

11. Feng GS, Chong K, Kumar A, Williams BRG: Identification of Double-Stranded RNA-Binding Domains in the InterferonInduced Double-Stranded RNA-Activated p68 Kinase. Proc Natl Acad Sci USA 1992, 89:5447-5451.

12. Green SR, Mathews MB: Two RNA-Binding Motifs in the Double-Stranded RNA-Activated Protein Kinase, DAl. Genes Dev 1992, 6:2478-2490.

13. Sharp TV, Schwemmle M, Jeffrey I, Laing $K$, Mellor $H$, Proud CG, Hilse K, Clemens M): Comparative Analysis of the Regulation of the Interferon-Inducible Protein Kinase PKR by EpsteinBarr Virus RNAs EBER-1 and EBER-2 and Adenovirus VA 1 RNA. Nucleic Acids Res1993, 19:4483-4490.

14. Davies MV, Chang HW, Jacobs BL, Kaufman RJ: The E3L and K3L Vaccinia Virus Gene Products Stimulate Translation through Inhibition of the Double-Stranded RNA-Dependent Protein Kinase by Different Mechanisms. J Virol 1993, 67:1688-1692.

15. Lloyd RM, Shatkin A): Translational Stimulation by Reovirus Polypeptide s3: Substitution for VAI RNA and Inhibition of Phosphorylation of the a Subunit of Eukaryotic Initiation Factor 2. $J$ Virol 1992, 66:6878-6884.

16. Lee TG, Tang N, Thompson S, Miller I, Katze MG: The 58,000Dalton Cellular Inhibitor of the Interferon-Induced DoubleStranded RNA-Activated Protein Kinase (PKR) is a Member of the Tetratricopeptide Repeat Family of Proteins. Mol Cell Biol 1994, 14:2331-2342.

17. Barber GN, Thompson $S$, Lee TG, Strom $T$, Jagus $R$, Darveau

-. A, Katze $G$ : The 58-Kilodalton Inhibitor of the Interferon-Induced Double-Stranded RNA-Activated Protein Kinase is a Tetratricopeptide Repeat Protein with Oncogenic Properties. Proc Natl Acad Sci USA 1994, 91:4278-4282.

Describes a unique cellular gene product that is activated upon influenza virus infection and inhibits PKR activation. Over-expression of this protein transforms NIH 3 T3 cells, possibly through inhibition of the putative tumor suppressor gene product, PKR.

18. Kumar A, Haque J, Lacoste J, Hiscott J, Williams BR: DoubleStranded RNA-Dependent Protein Kinase Activates Transcription Factor NF-KB by Phosphorylating IкB. Proc Natl Acad SCi USA 1994, 91:6288-6292

19. Maran A, Maitra RK, Kumar A, Dong B, Xiao W, Li G, Williams -. RG, Torrence PF, Silverman RH: Blockage of NF-KB Signaling by Selective Ablation of an mRNA Target by 2-5A Antisense Chimeras. Science 1994, 265:789-792.
Demonstrates a unique approach to degrade targeted mRNAs through coupling anti-sense oligonucleotides to $2 "-5$ ' oligoadenylate residues. The RNA is degraded through the $2^{\prime}-5^{\prime}$ oligoadenylate ribonuclease. This study shows that reduction in PKR RNA inhibits signaling through NF-KB The results suggest that PKR may signal through NF-KB.

20. Offermann MK, Hagan MK, Shaw R, Medford RM, Jagus R: Induction of Cellular Adhesion Moleculars by Double Stranded RNA in Human Umbilical Vein Endothelial Cells. J Immunol 1994, in press.

21. Mundschau LI, Faller DV: Oncogenic ras Induces an Inhibitor of Double-Stranded RNA-Dependent Eukaryotic Initiation Factor $2 \alpha$-Kinase Activation. J Biol Chem 1992, 267:23092-23098.

22. Judware R, Petryshyn R: Mechanism of Action of a Cellular Inhibitor of the dsRNA-Dependent Protein Kinase from 3T3F442A Cells. I Biol Chem 1992, 267:21685-21690.

23. Murtha-Riel P, Davies MV, Scherer BJ, Choi SY, Hershey JWB, Kaufman RJ: Expression of a Phosphorylation-Resistant Eukaryotic Initiation factor $2 \alpha$-Subunit Mitigates Heat Shock Inhibition of Protein Synthesis. / Biol Chem 1993, 268:12946-12951.

24. Ramaiah KVA, Davies $M$, Chen JJ, Kaufman RJ: Expression - of Mutant Eukaryotic Initiation Factor $2 \alpha$ Subunit (elF2 $\alpha$ ) Reduces Inhibition of Guanine Nucleotide Exchange Activity of elf-2B Mediated by elf-2 $\alpha$ Phosphorylation. Mol Cell Biol $1994,14: 4546-4553$.

Shows that expression of a Ser $51 \rightarrow$ Ala mutant of elF- $2 \alpha$ can prevent inhibition of protein synthesis upon heat shock and that this correlates with increased levels of elf-2B activity.

25. Wu S, Gupta S, Chatterjee N, Hileman RE, Chakrabarti D, Danslow ND, Merrick WC Kinzy TG, Osterman IC, Gupta NK: Cloning and Characterization of Complementary DNA Encoding the Eukaryotic Initiation Factor 2 (elf-2) Associated $67 \mathrm{kDa}$ Protein (p67). I Biol Chem 1993, 288: 10796-10801.

26. Matts RL, Hurst $R, X u Z$ : Denatured Proteins Inhibit Trans- lation in Hemin-Supplemented Rabbit Reticulocyte Lysate by Inducing the Activation of the Heme-Regulated elf-2 $\alpha$ Kinase. Biochemistry 1993, 32:7323-7328.

Demonstrates that HRI kinase interacts with $\mathrm{hsp} 70$ and that addition of denatured proteins elicits release and activation of HRI. The results have general implications for the control of kinase activity through interaction with heat-shock proteins.

27. Scheper GC, Voorma HO, Thomas AAM: Eukaryotic Initiation Factors-4E and -4F Stimulate $5^{\prime}$ Cap-Dependent as Well as Internal Initiation of Protein Synthesis. I Biol Chem 1992, 267:7269-7274.

28. Lazaris-Karatzas A, Sonenberg N: The mRNA 5' Cap-Binding Protein, eIF-4E, Cooperates with v-myc or ElA in the Transformation of Primary Rodent Fibroblasts. Mol Cell Biol 1992, 12:1234-1238.

29. Lazaris-Karatzas A, Smith MR, Frederickson RM, Jaramillo ML, Liu $Y$, Kung $H$, Sonenberg $N$ : Ras Mediates Translation Initiation Factor 4E-Induced Malignant Transformation. Genes Dev 1992, 6:1631-1642.

30. Rinker-Schaeffer CW, Graff IR, De Benedetti A, Zimmer SG, Rhoads RE: Decreasing the Level of Translation Initiation Factor 4E with Antisense RNA Causes Reveral of ras-Mediated Transformation and Tumorigenesis of Cloned Rat Embryo Fibroblasts. Int / Cancer 1993, 55:841-847.

31. Joshi-Barve S, De Benedetti, Rhoads RE: Preferential Translation of Heat Shock mRNAs in Hela Cells Deficient in Protein Synthesis Initiation Factors elf-4E and elF-4\%. I Biol Chem 1992, 267:21038-21043.

32. Klein PS, Melton DA: Induction of Mesoderm in Xenopus lae-. vis Embryos by Translation Initiation Factor 4E. Science 1994 265:803-806.

Over-expression of elf-4E is shown to induce mesoderm induction. A model is proposed where elF-4E increases translation of mesoderminducing factor, which acts in an autocrine manner to activate its receptor and stimulate differentiation through a ras-mediated pathway. 
33. Kaufman RJ, Murtha-Riel P, Pittman DD, Davies MV: Characterization of Wild-Type and Ser ${ }^{\mathbf{3 3}}$ Mutant Eukaryotic Initiation Factor 4E Overexpression in Mammalian Cells. I Biol Chem 1993, 268:11902-11909.

34 Pause A, Méthot N, Svitkin Y, Merrick WC, Sonenberg N: Dominant Negative Mutants of Mammalian Translation Initiation Factor elF-4A Define a Critical Role for elF-4F in Cap-Dependent and Cap-Independent Initiation of Translation. EMBO 1994, 13:1205-1215.

35. Pause A, Méthot N, Sonenber N. The HRIGRXXR Region of the DEAD Box RNA Helicase Eukaryotic Translation Initiation Factor 4A is Required for RNA Binding and ATP Hydrolysis. Mol Cell Biol 1993, 13:6789-6798.

36. Wimmer E, Hellen CUT, Cao X. Genetics of Poliovirus. Annu Rev Genet 1993, 27:353-436.

37. Meerovitch K, Sonenberg N: Internal Initiation of Picornavirus RNA Translation. Semin Virol 1993, 4:217-227.

38. Lamphear BJ, Yan R, Yang F, Waters D, Liebig HD, Klump $H_{\text {, }}$ Kuechler E, Skern T, Rhoads RE: Mapping the Cleavage Site in Protein Synthesis Initiation Factor elf-4 Gamma of the 2A Proteases from Human Coxsackievirus and Rhinovirus. I Biol Chem 1993, 268:19200-19203.

39. Kozak $M$ : Structural Features in Eukaryotic mRNAs that Modulate the Initiation of Translation. I Biol Chem 1991, 266:19867-19870.

40. Kozak M: A Consideration of Alternative Models for the Initiation of Translation in Eukaryotes. Crit Rev Biochem Mol Biol 1992, 27:385-402.

41. Ruan $\mathrm{H}$, Hill JR, Fatemie-Nainie S, Morris DR: Cell-Specific Translational Regulation of S-Adenosylmethionine Decarboxylase mRNA. / Biol Chem 1994, 269:17905-17910

42. Klausner RD, Rouault TA, Harford JB: Regulating the Fate of -. mRNA: The Control of Cellular Iron Metabolism. Cell 1993, 72:19-28

This is an excellent review on iron metabolism and control of ferritin translation by the IRE-BP. (See also [43].)

43. Daniels-McQueen S, Goessling LS, Thach RE: Inducible Expression Bovine Papillomavirus Shuttle Vectors Containing Ferritin Translational Regulatory Elements. Gene 1992, 122:271-279.

44. Jefferies HBJ, Reinhard C, Kozma SC, Thomas G: Rapamycin -. Selectively Represses Translation of the "Polypyrimidine Tract" mRNA Family. Proc Nall Acad Sci USA 1994, 91:4441-4445. A unique set of mRNAs that contain polypyrimidine tracts within their 5 UTR are preferentially translated upon phosphorylation of the ribosomal protein S6. Rapamycin selectively inhibits both $\mathbf{5 6}$ phosphorylation and translation of these mRNAs, and this may account for the immunosuppressant effects of rapamycin.

45. McBratney S, Chen CY, Sarnow P: Internal Initiation of Translation. Curr Opin Cell Biol 1993, 5:961-965.

46. Hellen CUT, Witherell GW, Schmid $M$, Shin SH, Pestova TV Gil A, Wimmer E: A Ctyoplasmic 57-kDa Protein that is Required for Translation of Picornavirus RNA by Internal Ribosomal Entry is Identical to the Nuclear Pyrimidine Tract-Binding Protein. Proc Natl Acad Sci USA 1993, 907642-7646.
47. Svitkin YV, Meerovitch K, Lee HS, Dholakia IN, Kenan D, Agol VI, Sonenberg N: Internal Translation Initiation on Poliovirus RNA: Further Characertization of La Function in Poliovirus Iranslation in Vitro. / Virol 1994, 68:1544-1550.

48. Davies MV, Kaufman R): Internal Translation Initiation in the Design of Improved Expression Vectors. Curr Opin Biotechnol $1992,3: 512-517$

49. Mountford P, Zevnik B, Duwel A, Nichols J, Li M, Dani C, Robertson $M$, Chambers I, Smith A: Dicistronic Targeting Constructs: Reporters and Modifiers of Mammalian Gene Expression. Proc Natl Acad Sci USA 1994, 91:4303-4307.

50. Macejak DG, Sarnow P: Internal Initiation of Translation Mediated by the $5^{\prime}$ Leader of a Cellular mRNA. Nature 1991, 353:90-94.

51. Oh SK, Scott MP, Sarnow P: Homeotic Gene Antennapedia mRNA Contains 5 '-Noncoding Sequences that Confer Translational Initiation by Internal Ribosome Binding. Cenes Dev 1992, 6:1643-1653.

52. Vagner S, Gensac M-C, Maret A, Bayard F, Amalric F, Prats H - Prats AC: Alternative Translation of Human Fibroblast Growth Factor-2 mRNA Occurs by Internal Entry of Ribosomes. $\mathrm{MO}$ Cell Biol 1994, in press.

An IRES is shown to control FGF-2 translation initiation by promoting translation at a CUG codon to yield a polypeptide that has a nuclear localization signal.

53. Patry $V$, Arnaud $E$, Amalric $F$, Prats $H$ : Involvement of Basic - Fibroblast Growth Factor $\mathbf{N H}_{2}$ Terminus in Nuclear Accumulation. Growth Factors 1994, in press.

The intracellular localization of newly synthesized FGF- 2 is determined by the utiliztion of specific initiation codons. Both AUG and CUG initiation codons are utilized in the translation of FGF-2 mRNA. The CUC initiation codon is upstream and encodes an extended polypeptide containing a nuclear localization that directs FGF-2 to the nucleus.

54. Prats $A C$, Vagner S, Prats $H$, Amalric F: cis-Acting Elements Involved in the Alternative Translation Initiation Process of Human Basic Fibroblast Growth Factor mRNA. Mol Cell Biol 1992, 12:4796-4805.

55. Jackson RI, Standart N: Do the Poly(A) Tail and $\mathbf{3}^{\prime}$ Untranslated Region Control mRNA Translation? Cell 1990, 62:15-24.

56. Munroe D, Jacobson A: mRNA Poly(A) Tail, a $3^{\prime}$ Enhancer of Translation Initiation. Mol Cell Biol 1990, 10:3441-3455.

57. Gallie DR, Tanguay R: Poly(A) Binds to Initiation Factors and - Increases Cap-Dependent Translation in Vitro. / Biol Chem 1994, 269:17166-17173.

One of the first papers suggesting that a possible link between translation initation at the $5^{\prime}$ end of the mRNA and poly(A) at the $3^{\prime}$ end of the mRNA may be mediated through interactions with elF-4F and elF-4B.

RJ Kaufman, Howard Hughes Medical Institute, Department of Biological Chemistry, University of Michigan Medical Center, Ann Arbor, Michigan 48105, USA. 